Vincenzo Leuzzi, MD

Roberto Micheli, MD

Daniela D'Agnano, MD

Anna Molinaro, PT

Tullia Venturi, PT

Alessandro Plebani, MD

Annarosa Soresina, MD

Mirella Marini, MD

Pierino Ferremi Leali, MD

Isabella Quinti, MD

Maria C. Pietrogrande, MD

Andrea Finocchi, MD

Elisa Fazzi, MD

Luciana Chessa, MD

Mauro Magnani, MD

Correspondence to

Dr. Leuzzi:

vincenzo.leuzzi@uniroma1.i

\section{Positive effect of erythrocyte-delivered dexamethasone in ataxia-telangiectasia}

\section{OPEN}

\section{ABSTRACT}

Objective: Ataxia-telangiectasia (AT) is a rare, devastating neurodegenerative disease presenting with early-onset ataxia, oculocutaneous telangiectasia, immunodeficiency, radiosensitivity, and proneness to cancer. In a previous phase 2 study, we showed that 6 monthly infusions of autologous erythrocytes loaded with dexamethasone (EryDex; EryDel, Urbino, Italy) were effective in improving neurologic impairment in young patients with AT. The present article reports the results of the extension of this study for an additional 24-month period.

Methods: After the end of the first trial, 4 patients continued to be treated with monthly EryDex infusions for an additional 24 months, and their clinical outcome was compared with that of 7 age-matched patients who stopped the treatment after the first 6 infusions. The protocol included serial assessment of ataxia (by International Cooperative Ataxia Rating Scale) and adaptive behavior (by Vineland Adaptive Behavior Scales) and clinical and laboratory tests revealing treatment- and steroid-dependent adverse effects, if present.

Results: Patients in the extended study experienced a continuous neurologic improvement with respect to their pretreatment status, whereas controls showed a progressive neurologic deterioration (according to the natural history of the disease) after the discontinuation of the treatment. The delivery system we adopted proved to be safe and well-tolerated, and none of the side effects usually associated with the chronic administration of corticosteroids were observed during the entire trial.

Conclusions: These promising preliminary results call for a large-scale controlled study on protracted treatment of patients with AT with dexamethasone-loaded erythrocytes. Neurol Neuroimmunol Neuroinflamm 2015;2:e98; doi: 10.1212/NXI.0000000000000098

\section{GLOSSARY}

AT = ataxia-telangiectasia; $\mathbf{A T M}=$ ataxia telangiectasia mutated; DSP $=$ dexamethasone phosphate; ICARS = International Cooperative Ataxia Rating Scale; VABS = Vineland Adaptive Behavior Scales.

Ataxia-telangiectasia (AT) is a rare genetic disease ${ }^{1,2}$ caused by mutations in the ataxia telangiectasia mutated $(A T M)$ gene, which results in a multisystemic disorder presenting with early-onset ataxia, oculocutaneous teleangiectasias, progressive supranuclear ophthalmoplegia, immunodeficiency, recurrent sinopulmonary infections, radiosensitivity, and proneness to cancer. In the classic form, patients are wheelchair-dependent by the age of 10 years, ${ }^{1}$ and their life expectancy is approximately 25 years. ${ }^{1,2}$ No effective disease-modifying therapy is presently available.

Observational studies have suggested that betamethasone may be effective in improving neurologic functions in patients with $\mathrm{AT}^{3,4} \mathrm{~A}$ controlled short-term trial confirmed the efficacy of

From the Department of Pediatrics, Child Neurology and Psychiatry (V.L., D.D., T.V.), Department of Molecular Medicine (I.Q.), and Department of Clinical and Molecular Medicine (L.C.), Sapienza University of Rome, Italy; Unit of Child Neurology and Psychiatry (R.M., E.F.), Department of Clinical and Experimental Sciences, Pediatrics Clinic (A.P., A.S., M. Marini, P.F.L.), and Institute of Molecular Medicine A. Nocivelli (A.P., A.S., M. Marini, P.F.L.), Spedali Civili and University of Brescia, Brescia, Italy; School in Reproductive and Developmental Science (A.M.), University of Trieste and University of Brescia, Brescia, Italy; Department of Pediatrics (M.C.P.), University of Milan, Fondazione IRCCS Ca' Granda, Milan, Italy; Department of Pediatrics (A.F.), Bambino Gesù Children's Hospital and University of Tor Vergata, Rome, Italy; Department of Biomolecular Sciences (M. Magnani), University of Urbino “Carlo Bo,” Urbino, Italy; and EryDel SpA (M. Magnani), Urbino, Italy.

Funding information and disclosures are provided at the end of the article. Go to Neurology.org/nn for full disclosure forms. The Article Processing Charge was paid by EryDel SpA.

This is an open access article distributed under the terms of the Creative Commons Attribution-Noncommercial No Derivative 3.0 License, which permits downloading and sharing the work provided it is properly cited. The work cannot be changed in any way or used commercially. 


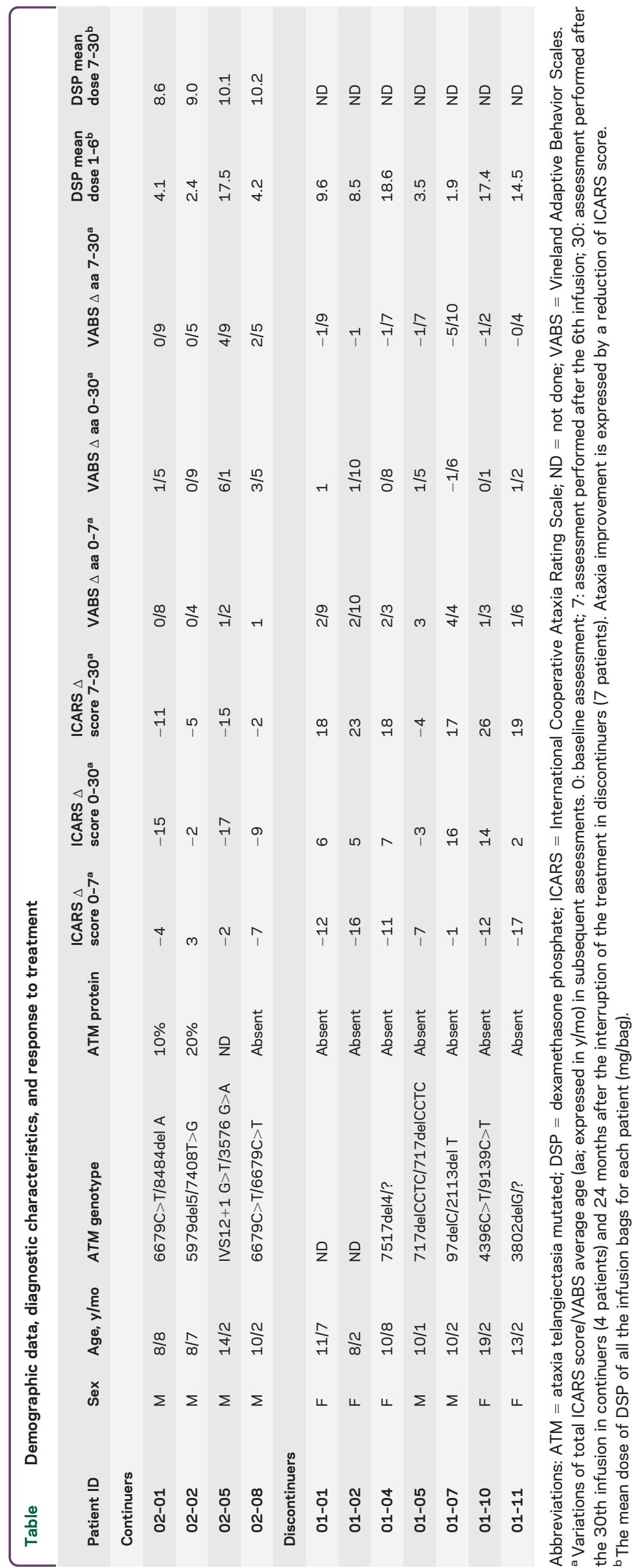

oral betamethasone $(0.1 \mathrm{mg} / \mathrm{kg}),{ }^{5}$ but corticosteroid side effects were quickly observed. To overcome these side effects and explore the effects of a more protracted treatment on neurologic outcome, we recently performed a single-arm, open-label, 6-month extended phase 2 trial in which the enrolled patients received a monthly treatment of $50 \mathrm{~mL}$ of autologous erythrocytes loaded with 2 vials of $250 \mathrm{mg}$ of dexamethasone phosphate (DSP) by EryDex (EryDel, Urbino, Italy) procedure. ${ }^{6}$ Similarly to betamethasone, dexamethasone has a high anti-inflammatory potency and lacks mineralcorticoid activity. DSP is converted to dexamethasone by erythrocytes' phosphatases and released into the bloodstream for about 20-30 days. ${ }^{7}$

After 6 infusions, patients experienced a clinical improvement of about 5 points on the International Cooperative Ataxia Rating Scale (ICARS) ${ }^{8}$ and a significant improvement in adaptive behavior, assessed by Vineland Adaptive Behavior Scales (VABS), ${ }^{9}$ without the occurrence of steroid-dependent adverse events. The improvement was more relevant in patients presenting with less severe neurologic impairment and was affected by the efficiency of the DSP loading procedure into erythrocytes. ${ }^{6}$ We report the results of the extension of this preliminary study for an additional 24-month period.

METHODS At the end of the first 6-month trial, ${ }^{6} 4$ male patients (mean age 10.6 years; SD 2.8 years; range 8.7-14.2 years) requested and were authorized by the Ethic Committee to continue EryDex treatment. So far they have been treated monthly for an additional 24-month period. The ICARS and VABS scores of the patients in the extended study before the beginning of the treatment and after 6 and 24 EryDex infusions were compared with those of the 7 patients with AT ( 2 male, 5 female; mean age 11.8 years; SD 3.5 years; range $8.2-19.2$ years) who stopped the treatment after the sixth infusion, as originally planned by the study design. ${ }^{6}$ In accordance with a drug compassionate use clause, the selection of the continuers was based on the parents' decision (i.e., no external inclusion criterion could be applied), and the controls were selected among discontinuers by trying to best match the clinical characteristics of the continuers (table). During the extension study, the loading procedure was further optimized by obtaining an encapsulated DSP of $9.4 \pm 0.8 \mathrm{mg} / \mathrm{bag}$ (vs $6.7 \pm$ 6.9 in the previous study ${ }^{6}$ ) with the same dose of the medicament. The assessment also included clinical and laboratory tests aimed at detecting treatment- and steroid-dependent adverse effects.

Standard protocol approvals, registrations, and patient consents. The extension was authorized by the Ethic Committee. Current Controlled Trial registration 2010-02231519SpA. 
Figure Neurologic impairment variation and duration of the treatment in patients with ataxia-telangiectasia

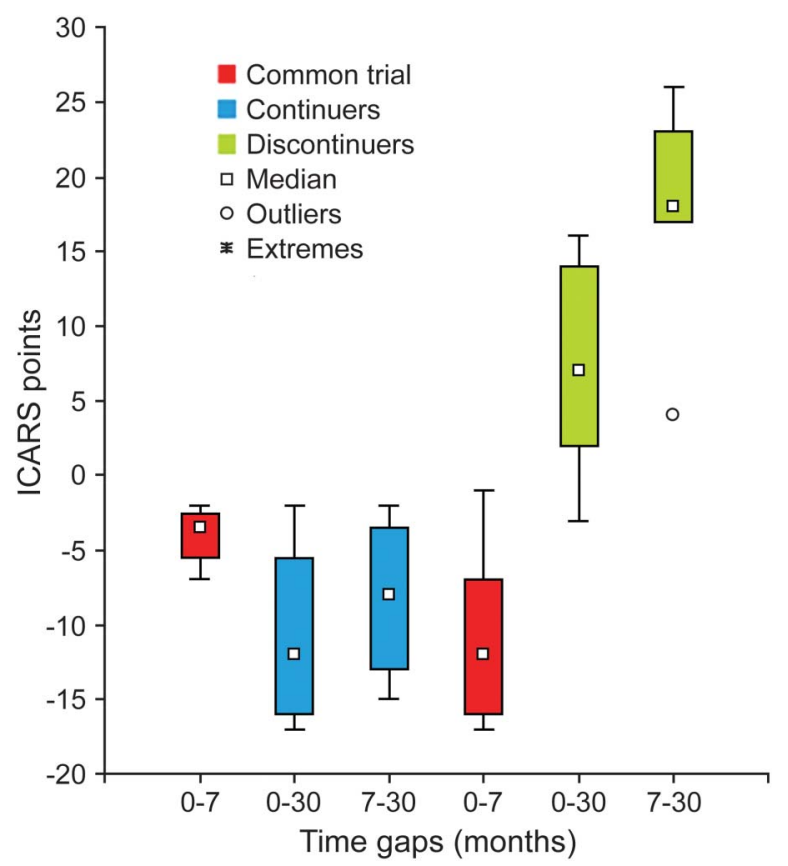

The trend of International Cooperative Ataxia Rating Scale (ICARS) score variations (with $\mathrm{SD}$ ) in 4 patients with ataxia-telangiectasia who were treated for 30 months with monthly infusions of autologous dexamethasone phosphate-loaded erythrocytes compared with the ICARS scores of 7 patients who discontinued the treatment after the first 6 monthly infusions. 0 (baseline), 7 (after the first 6 infusions), and 30 (after 30 months) represent the scheduled time points for the subsequent assessments. In continuers, 30 is also the total number of infusions before the last evaluation. In red is the common trial (0-7) for all 11 patients, in blue are the ICARS score variations in 4 continuers (0-30; 7-30), and in green are the ICARS score variations in 7 discontinuers $(0-30 ; 7-30)$. The increase of the score reflects the worsening of ataxia.

RESULTS The table summarizes the clinical response to the treatment at the end of the first 6 months (11 patients) and after 24 further months in continuers ( 4 male patients) and discontinuers (7 patients; 2 male, 5 female). The mean DSP incorporation during both the original and extended trials is also shown. At the end of the first 6-month trial, ICARS and VABS scores of continuers and discontinuers were ICARS $52.2 \pm 7.1$ vs $43 \pm 2.9$ and VABS $6 \pm 2.3$ vs $8.2 \pm 0.6$, respectively.

After 30 months, the patients in the extended study experienced an improvement in ICARS score of 10.7 points (SD 6.75; range 2-17) with respect to the score obtained at basal clinical evaluation. Conversely, the ICARS score of the 7 patients who discontinued the treatment worsened by 6.7 points (SD 6.5; range +3-16) (Mann-Whitney $U=1.00 ; z=2.45 ; p=$ 0.013803). Moreover, all continuers and only 1 of 7 discontinuers improved their ICARS score (Fisher exact test, $p=0.0152$ ). Correspondingly, VABS average age improved by 2.10 years (SD 2.4 years; range 9 months6.1 years) and by 0.9 years (SD 1 year; range -1.6 to +1.10 years) in continuers and discontinuers, respectively (Mann-Whitney $U=5.50 ; z=1.60$; $p=0.10$ ). Moreover, ICARS scores at the end of the first 6-month trial and after 30 months improved by 8.2 points (SD 5.8; range 2-17) in the continuers and worsened by 17.8 points (SD 6.9, range $-4-26$ ) in the discontinuers (Mann-Whitney $U=0.00 ; z=2.64$; $p=0.008)$. Ataxia improved in 4 of 4 continuers and in 1 of 7 discontinuers (Fisher exact test, $p=0.015$ ) (figure). Concomitant variations in VABS among continuers and discontinuers were 2.6 years (SD 2.3 years; range $0.5-4.9$ years) and -1.7 years (SD 11 months; range -4 months +2.9 years), respectively (MannWhitney $U=0.00 ; z=2.64 ; p=0.008$ ).

No steroid-dependent adverse reactions were observed during the entire treatment period. Standard laboratory tests, physical examination, vital signs, and ECG were all normal. Additional laboratory parameters such as cholesterol (total, high-density lipoprotein, and low-density lipoprotein), glycosylated hemoglobin (HbA1c), and blood and urinary cortisol were all within the normal range. $\mathrm{CD}^{+}$lymphocyte count remained stable during the treatment period but below the normal range for 3 of the 4 patients. Blood $\alpha$-fetoprotein levels increased in all patients, regardless of the treatment they underwent.

DISCUSSION Long-term corticosteroid administration is effective in slowing the progression of Duchenne muscular dystrophy. ${ }^{10}$ We recently reported a statistically significant improvement in ataxic symptoms with DSP-loaded red cells in a cohort of young patients with AT. ${ }^{6}$ Although this new treatment did not have the usual side effects of chronic steroid treatment, it was apparently less effective then oral betamethasone treatment, which resulted in a median improvement of 13 points on the ICARS after a month of therapy. ${ }^{5}$ Present data are more encouraging, showing that after 30 months of treatment the patients experienced an improvement of 10.7 points in mean ICARS score and 3 years in VABS average age with respect to their basal condition. Conversely, the ICARS score of the discontinuers at 30 months had worsened by 6.7 points and the VABS average age had improved just 0.9 years. The gap of 26 ICARS points between continuers and discontinuers at 30 months with respect to the score obtained by the 2 groups after the first 6 months of treatment is an important finding.

Albeit preliminary, the present results are important: 2.5 years is a time span long enough to disclose the progressive neurologic impairment that characterizes the natural clinical history of AT., ${ }^{1,2}$ The fact that the discontinuers experienced a decline of their neurologic conditions once steroids were interrupted would suggest a symptomatic effect of the treatment rather than a plastic change involving the basic pathogenetic 
mechanism of the disease. Otherwise, the persistent clinical improvement we observed so far in the continuers conflicts with this hypothesis.

Several methodologic limitations (lack of blinding and placebo in the treatment assignation, small size of the sample, lack of external clinical criteria for patient enrollment) affect our study, which was based on an empiric post hoc observation. The lack of AT-dedicated rating scales is a further intrinsic methodologic limitation. Nevertheless, in the face of such a dramatic, untreatable disease, any clinical observation suggesting a potential treatment deserves to be considered.

Whatever the biological effect of steroids in AT, present data support the view that a protracted treatment may delay and perhaps bias the natural course of the disease. Moreover, the delivery system we adopted was confirmed to be safe and well-tolerated, since after this extended period of time no side effects could be detected. A large-scale controlled study on protracted steroid treatment by DSP loaded into erythrocytes in patients with AT is mandatory in order to verify these preliminary data.

\section{AUTHOR CONTRIBUTIONS}

All authors have made a substantial contribution to qualify for authorship. Each author listed on the manuscript has seen and approved the submission of this version of the manuscript and takes full responsibility for the manuscript. Vincenzo Leuzzi: drafting/revising the manuscript, analysis and interpretation of clinical and biochemical data, acquisition of data. Roberto Micheli: drafting/revising the manuscript, analysis and interpretation of clinical and biochemical data, acquisition of data. Daniela D'Agnano: drafting/revising the manuscript, analysis and interpretation of clinical and biochemical data, acquisition of data. Anna Molinaro: drafting/revising the manuscript, analysis and interpretation of clinical and biochemical data, analysis and interpretation of patients' neuromotor patterns. Tullia Venturi: drafting/revising the manuscript, analysis and interpretation of clinical and biochemical data, analysis and interpretation of patients' neuromotor patterns. Alessandro Plebani: drafting/revising the manuscript, analysis and interpretation of clinical and biochemical data. Annarosa Soresina: drafting/revising the manuscript, analysis and interpretation of clinical and biochemical data. Mirella Marini: drafting/revising the manuscript, analysis and interpretation of clinical and biochemical data. Pierino Ferremi Leali: drafting/revising the manuscript, analysis and interpretation of clinical and biochemical data. Isabella Quinti: drafting/revising the manuscript, analysis and interpretation of clinical and biochemical data. Maria C. Pietrogrande: drafting/ revising the manuscript, analysis and interpretation of clinical and biochemical data. Andrea Finocchi: drafting/revising the manuscript, analysis and interpretation of clinical and biochemical data. Elisa Fazzi: drafting/ revising the manuscript, analysis and interpretation of clinical and biochemical data, analysis and interpretation of patients' neuromotor patterns. Luciana Chessa: drafting/revising the manuscript, analysis and interpretation of clinical and biochemical data, molecular analysis interpretation. Mauro Magnani: drafting/revising the manuscript, analysis and interpretation of clinical and biochemical data, acquisition of data.

\section{ACKNOWLEDGMENT}

The authors thank Drs. L. Buccone, C. Pignata, F. Specchia, and A. Trizzino for referring patients; the associations (Amici di Valentina, Noi per Lorenzo, AISA, AIP) that assisted the families in traveling and staying in Rome or Brescia; all the hospital personnel (doctors, nurses, physiotherapists, technicians, etc.); and the sponsor EryDel for providing economic support and the EryDex system.

\section{STUDY FUNDING}

EryDel provided economic support and the EryDex System.

\section{DISCLOSURE}

V. Leuzzi, R. Micheli, D. D'Agnano, A. Molinaro, T. Venturi, A. Plebani, A. Soresina, M. Marini, and P. F. Leali report no disclosures. I. Quinti is on the scientific advisory board for CSL Behring, is on the editorial board for Frontiers in Immunology, and received research support from Jeffrey Modell Foundation. M.C. Pietrogrande reports no disclosures. A. Finocchi received research support from Italian Ministry of Health. E. Fazzi and L. Chessa report no disclosures. M. Magnani is the CSO of EryDel SpA, holds a patent for encapsulation of agents within erythrocytes, received research support from Fondazione Cassa di Risparmio di Fano, and holds stock in EryDel SpA. Go to Neurology.org/nn for full disclosure forms.

Received October 22, 2014. Accepted in final form March 5, 2015.

\section{REFERENCES}

1. Sedgwick O, Boder E. Ataxia-teleangiectasia. In: Vinken PJ, Bruyn GW, editors. Handbook of Clinical Neurology. Vol 14. Amsterdam: Elsevier; 1972: 267-239.

2. Ataxia-Teleangiectasia; AT, \#208900. Online Mendelian Inheritance in Man (OMIM), Center for Medical Genetics, John Hopkins University, Baltimore, MD, and the National Center for Biotechnology Information, National Library of Medicine, Bethesda, MD. Available at: http:// omim.org/entry/208900. Accessed October 24, 2012.

3. Buoni S, Zannolli R, Sorrentino L, Fois A. Betamethasone and improvement of neurological symptoms in ataxia telangiectasia. Arch Neurol 2006;63:1469-1482.

4. Broccoletti T, Del Giudice E, Cirillo E, et al. Efficacy of very-low-dose betamethasone on neurological symptoms in ataxia-telangiectasia. Eur J Neurol 2011;18: 564-570.

5. Zannolli R, Buoni S, Betti G, et al. A randomized trial of oral betamethasone to reduce ataxia symptoms in ataxia telangiectasia. Mov Disord 2012;27:1312-1316.

6. Chessa L, Leuzzi V, Plebani A, et al. Intra-erythrocyte infusion of dexamethasone reduces neurological symptoms in ataxia teleangiectasia patients: results of a phase 2 trial. Orphanet J Rare Dis 2014;9:5.

7. Magnani M, Rossi L, D’ascenzo M, Panzani I, Bigi L, Zanella A. Erythrocyte engineering for drug delivery and targeting. Biotechnol Appl Biochem 1998;28:1-6.

8. Trouillas P, Takayanagi T, Hallett M, et al. International Cooperative Ataxia Rating Scale for pharmacological assessment of the cerebellar syndrome. The Ataxia Neuropharmacology Committee of the World Federation of Neurology. J Neurol Sci 1997;145:205-211.

9. Van Duijn G, Dijkxhoorn Y, Noens I, Scholte E, van Berckelaer-Onnes I. Vineland Screener 0-12 years research version (NL). Constructing a screening instrument to assess adaptive behaviour. Int J Methods Psychiatr Res 2009;18:110-117.

10. Moxley RT III, Ashwal S, Pandya S, et al; Quality Standards Subcommittee of the American Academy of Neurology, Practice Committee of the Child Neurology Society. Practice parameter: corticosteroid treatment of Duchenne dystrophy: report of the Quality Standards Subcommittee of the American Academy of Neurology and the Practice Committee of the Child Neurology Society. Neurology 2005;64:13-20. 


\section{Neurology \\ Neuroimmunology \& Neuroinflammation}

\section{Positive effect of erythrocyte-delivered dexamethasone in ataxia-telangiectasia \\ Vincenzo Leuzzi, Roberto Micheli, Daniela D'Agnano, et al. \\ Neurol Neuroimmunol Neuroinflamm 2015;2; \\ DOI 10.1212/NXI.0000000000000098}

This information is current as of April 9, 2015

\section{Updated Information \& Services}

References

Subspecialty Collections

Permissions \& Licensing

\section{Reprints}

including high resolution figures, can be found at:

http://nn.neurology.org/content/2/3/e98.full.html

This article cites 9 articles, 0 of which you can access for free at: http://nn.neurology.org/content/2/3/e98.full.html\#\#ref-list-1

This article, along with others on similar topics, appears in the following collection(s):

All Clinical trials

http://nn.neurology.org//cgi/collection/all_clinical_trials

All Practice Management

http://nn.neurology.org//cgi/collection/all_practice_management

Information about reproducing this article in parts (figures,tables) or in its entirety can be found online at:

http://nn.neurology.org/misc/about.xhtml\#permissions

Information about ordering reprints can be found online:

http://nn.neurology.org/misc/addir.xhtml\#reprintsus

Neurol Neuroimmunol Neuroinflamm is an official journal of the American Academy of Neurology.

Published since April 2014, it is an open-access, online-only, continuous publication journal. Copyright $(\subset$ 2015 American Academy of Neurology. All rights reserved. Online ISSN: 2332-7812.

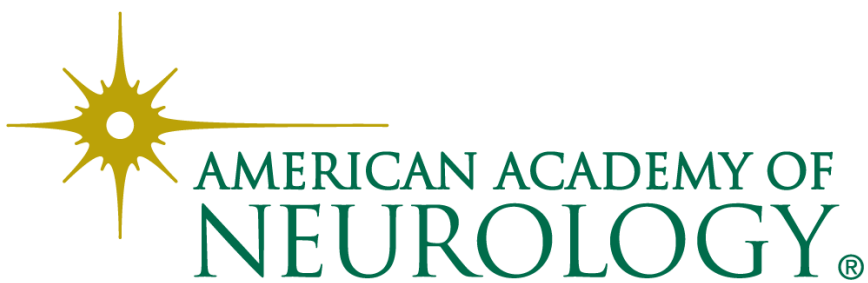

